IMAGE

UNAVAILABLE

FOR COPYRIGHT

REASONS

Fielding queries: studies of soybeans suggest plants will suffer from increased concentrations of near-surface ozone produced by global warming.

\title{
Hikes in surface ozone could suffocate crops
}

Jim Giles, London

If farmers don't adapt, changing environmental conditions could damage food production. That's the disturbing message from the first open-air simulations of Earth's dimate in 2050, which suggest that negative effects of increasing surface ozone will outweigh any benefits triggered by warming.

Rising carbon-dioxide levels had previously led researchers to make rosy predictions about cropyields in coming decades the gas promotes growth by increasing rates of photosynthesis, among other effects. But much of the work has been based on greenhouse trials and has ignored the impact of ozone concentrations near the ground. When researchers from the University of Illinois at UrbanaChampaign addressed this shortcoming in field trials of soya plants, they saw yields dive.

The result is a concern because the world's two largest soybean growers may face significant ozone increases, says crop scientist and study author Stephen Long. Urban air pollutants are expected to push up levels of near-surface ozone by at least $25 \%$ by the middle of this century, but rises in China and in the US Midwest, where almost 300,000 square kilometres of soybeans are harvested annually - could be two to three times as great.

Ozone creates reactive molecules that destroy rubisco, an enzyme crucial for photosynthesis. It is also known to make leaves age faster. To investigate its effects, the Illinois team developed open-air experiments in which carbon dioxide and ozone were released from pipes that surrounded 16 plots of 200 square metres. By using wind sensors to control gas release, concentrations in the air over the plot were held close to the predicted 2050 levels over the three-year study.

The preliminary data, presented at a

Royal Society conference held over 26-27 April in London, suggests that yields will be cut by up to $10 \%$. Previous forecasts of crop yields made by the Intergovernmental Panel on Climate Change (IPCC) should now be revised, warns Long. "No agrochemical company would use [greenhouse trials] to forecast how their chemical will affect crops, yet we use them to predict global food security," he complains.

The open-air studies revealed further threats that greenhousework had not spotted,

\section{Changing ozone levels}

50

Increase from 2000 to 2100 (parts per billion)

0

including delayed maturation, which puts crops at risk of frost late in the season. And pests prospered. ${ }^{\alpha}$ The IPCC predicts that chewing insects will do worse in higher carbon dioxide," notes Long. "Unfortunately Japanese beetles like the environment. They livelonger and produce more eggs."

\section{The long view}

All of the 22 soya varieties that Long tested showed a similar response to the conditions, suggesting that it might be hard to breed strains with better ozone tolerance. Within decades farmers may have to adapt by growing different crops, although without further studies it is unclear how other types of plant are likely to be affected.

"Ozone will be a threat," agrees John Porter, an ecologist at the Royal Veterinary and Agricultural University in Taastrup, Denmark. He says that it is likely to be a particular problem in countries that are rapidly industrializing, such as India and China (seemap).

At first, dropping yields would not be serious for developed regions such as Europe, where countries can import food and farmers are not pushed for the highest possible yields. But Porter points out that if other nations reduce production owing to ozone pollution, Europe may have to compensate.

Climate researchers are urgently working on ways to help farmers plan ahead. One approach is to combine climate simulations with software that models crop yields, to predict agricultural boom or bust.

Results from DEMETER, one of the most sophisticated models so far, are published in a series of papers in this month's Tellus. The EU-funded project forecasts growing-season weather using data fromrecent years. It runs multiple climate models and data sets at the same time - a technique known as ensemble modelling that has been widely adopted over the past few years as a way to cope with differing predictions from individual simulations. The outputs are then plugged into models of crop production. When tested for European wheat, DEMETER predictions averaged within $5.9 \%$ of the actual yield (Cantelaube, P. \& Terres, J.-M. Tellus A57,476-487; 2005).

The approach is still in its infancy. But reliable crop forecasts could eventually benefit everyone from subsistence farmers to administrators. Farmers might, for example, choose not to plant a crop that is predicted to fail. And European Commission officials, who are showing an interest in the DEMETER model of wheat production, could adjust the payments they make to farmers to reflect which crops the continent is predicted to need in a given year. 